\title{
Fetomaternal outcome in fibroid complicating pregnancy: a retrospective study
}

\author{
Suneela Mullakkal Sankaran, Jayasree Sukumara Pillai*
}

Department of Obstetrics and Gynaecology, Government Medical College, Kozhikode, Kerala, India

Received: 14 May 2021

Accepted: 29 May 2021

\section{*Correspondence:}

Jayasree Sukumara Pillai,

E-mail: drjayasreerajmohan@gmail.com

Copyright: (c) the author(s), publisher and licensee Medip Academy. This is an open-access article distributed under the terms of the Creative Commons Attribution Non-Commercial License, which permits unrestricted non-commercial use, distribution, and reproduction in any medium, provided the original work is properly cited.

\begin{abstract}
Background: Fibroids are the commonest benign tumour arising from the smooth muscle from uterus. Effects of fibroids on pregnancy and the effects of pregnancy on fibroids are a frequent clinical concern since these tumors are common in women of reproductive age. Most pregnant women with fibroids do not have any complications during pregnancy related to the fibroids. Pain is the most common problem and there may be a slightly increased risk of obstetrical complications like miscarriage, preterm labor and delivery, malpresentation and placental abruption.

Methods: A retrospective study was carried out to study the fetomaternal complications in fibroid complicating pregnancies. Duration of study period was one year. Study was from 1 January 2019 to 31 December 2019 in government medical college, Kozhikode. Patients beyond 28 weeks of gestational age with fibroid complicating pregnancies were included. Case records were reviewed from medical records library government medical college, Kozhikode. Detailed review of patients including history, examination and ultrasound scan reports, mode of delivery, antepartum, intrapartum, postpartum complications and details of babies were also taken.

Results: During the study period a total of 112 cases of fibroid complicating pregnancies were included in the study out of 15875 total number of deliveries. Majority of patients belonged to age group between 30 to 35 years (40.17\%) and $28.1 \%$ belonged to between 35 and40 years. $63.39 \%$ of patients were multies. In most of the cases fibroid was diagnosed by the first trimester ultra sound itself. Size of uterus remained corresponding to gestational age in more than half of cases $(56.25 \%)$. There was increased incidence of caesarean delivery $(56.25 \%)$, preterm delivery $(7.2 \%)$ and placenta praevia $(2.8 \%)$ postpartum haemorrhage $(10.71 \%)$ in the studied cases.

Conclusions: Fibriod complicating pregnancies are associated with higher incidence of obstetric complications during all the phases of pregnancy. Proper antenatal care and assessment can reduce the adverse outcomes to a greater extent.
\end{abstract}

Keywords: Fibroid, Fetomaternal, Ultrasound, Gestational age, Obstetric complications

\section{INTRODUCTION}

Fibroids, also known as leiomyomas, are common benign tumors arising from myometrium. It is an estrogen dependant tumor and is commonly seen in $30-55 \%$ women of reproductive age group. ${ }^{1}$ Incidence of fibroids in pregnancy ranges from 0.1 to $10.7 \%$ of all pregnancies. ${ }^{2}$ Of fibroids only $50 \%$ are symptomatic, hence true prevalence may be high. ${ }^{3}$ Incidence of fibroids increases with maternal age especially more than 35 years and in nulliparous women. ${ }^{4}$ Symptoms of myoma depends on site and size. They can present with menstrual symptoms, pelvic pain, pressure symptoms, interference with reproductive function. Around $30 \%$ of women with fibroids will have menstrual abnormalities and pelvic pan. Pelvic pain is common to other conditions also. Pressure symptoms caused mainly by cervical fibroids or anterior wall fibroids leading to urinary symptoms like acute 
retention. Myomas impacted in pouch of douglas can cause constipation. Because of the growing trend of delayed childbearing, the incidence of fibroids in older women undergoing treatment for infertility is reportedly $12 \%$ to $25 \% .^{3}$ The ability of ultrasound to detect fibroids in pregnancy is limited $(1.4 \%-2.7 \%)$ primarily due to the difficulty of differentiating fibroids from physiologic thickening of themyometrium. ${ }^{4-6}$

Diagnosis of fibroid during pregnancy is not that easy as fibroid may by mistake be diagnosed as myometrial thickening and hence true incidence of fibroids in pregnancy is under estimated. ${ }^{4-7}$ Studies have shown that around $60-80 \%$ of fibroids do not show any significant change in pregnancy. Among those fibroids which increase in pregnancy maximum increase occurs in first trimester and that in the first 10 weeks of gestation. About 10 to $30 \%$ of fibroids will develop complications during pregnancy. ${ }^{8,9}$ Pregnancy complications commonly seen are abortion, antepartum haemorrhage, retention of urine, abruption, malpresentations, fetopelvic disproportion, premature rupture of membranes, retained placenta, postpartum haemorrhage, preterm delivery, low birth weight, dysfunctional labour, increased operative delivery. ${ }^{10}$ Uterine fibroids also can lead to infertility, puerperal sepsis and uterine inversion.

Fibroids undergo red degeneration in pregnancy which present clinically with acute abdominal pain. ${ }^{11}$ The majority of fibroids (60\%-78\%) do not demonstrate any significant change in volume during pregnancy. ${ }^{12}$ Of the $22 \%$ to $32 \%$ of fibroids that did increase in volume, the growth was limited almost exclusively to the first trimester, with very little if any growth in the second and third trimesters. Some studies have shown that small fibroids are just as likely to grow as large fibroids, whereas other studies have suggested that small and large fibroids $(6 \mathrm{~cm})$ have different growth patterns in the second trimester (small fibroids grow whereas large fibroids remain unchanged or decrease in size), but all decrease in size in the third trimester. ${ }^{12-14}$ The majority of fibroids show no change during the puerperium, although $7.8 \%$ will decrease in volume by up to $10 \% .^{12,13}$

The severe pain associated with red degeneration is thought to be due the rapid fibroid growth which results in the tissue outgrowing its blood supply leading to tissue anoxia, necrosis and infarction of the growing uterus results in a change in the architecture (kinking) of the blood supply to the fibroid leading to ischemia and necrosis even in the absence of fibroid growth or the pain results from the release of prostaglandins from cellular damage within the fibroid. ${ }^{15-17}$ The location of the fibroid determines the risk for bleeding. Bleeding in early pregnancy is significantly more common if the placenta implants close to the fibroid. ${ }^{18,19}$

Concurrent myomectomy can be performed in selected cases. In some patients complications like paralytic ileus, postoperative atonic haemorrhage, blood transfusions, slightly prolonged duration of hospital stay have been reported. ${ }^{20-22}$

\begin{abstract}
Aim
The aim of the study was to identify fetomaternal complications in fibroid complicating pregnancy for 1 year period.
\end{abstract}

\section{METHODS}

\section{Setting}

This was a retrospective cross sectional study conducted in the department of Obstetrics and Gynaecology, Government Medical College, Kozhikode.

All cases of fibroid complicating pregnancies getting admitted for 1 year period, from 1 January 2019 to 31 December 2019 were included. Case records were reviewed from institutional medical records library.

\section{Inclusion criteria}

All cases beyond 28 weeks of gestation complicated by fibroid were included.

\section{Exclusion criteria}

Patients with multiple pregnancy were excluded from the study.

All patients admitted with fibroid complicating pregnancies were included in the study. A detailed history regarding symptoms of fibroid, previous treatment for infertility including surgery if any, clinical and USG findings before and during pregnancy if available from records were reviewed. Serial clinical examination and imaging during pregnancy were also noted. Obstetric complications like caesarean delivery, malpresentation, preterm delivery, placenta previa, abruptio placentae, premature rupture of membranes, incidental myomectomy, postpartum haemorrhage, blood transfusion, postoperative complications, duration of surgery and duration of hospital stay were studied. Any increase or decrease in size of fibroid, fetal complications like incidence of IUGR, malpresentations, low birth weight, NICU admission were also studied.

\section{Statistical analysis}

Qualitative data were expressed as number and percentage, and quantitative data as mean and standard deviation.

\section{RESULTS}

This study was conducted from 1 January 2019 to 31 December 2019. Of the cases reviewed during the period there were total 112 cases belonging to the study out of 15875 number of deliveries. Of the total patients' majority 
belonged to age group of more than 30 years. $40.17 \%$ between 30 to 35 years, $26.7 \%$ between 35 to 40 years $2.67 \%$ belonged to age group between 40 to 45 years, $28.1 \%$ belonged to age group between 25 to 30 years and $3.57 \%$ below 25 years (Figure 1 ).

$63.39 \%$ of cases were multies and $36.6 \%$ primies (Figure 2).

More than half of the patients were with BMI above 25, about $58.3 \%$ (Figure 3 ).

In about $66.07 \%$ of cases fibroid was diagnosed for the first time during antenatal ultra-sonography and in $33.9 \%$ it was pre-existing. In $70.53 \%$ fibroid was diagnosed in first trimester scan itself, $29.46 \%$ of cases fibroid diagnosed only by second trimester ultrasound, in $3.57 \%$ by third trimester ultrasound (Figure 4).

Of the total 112 cases history of treatment for fibroid prior to pregnancy was there in $15.17 \%$ of cases, of that only $5.3 \%$ gives history of prior surgical treatment. $9.8 \%$ of cases had history of infertility. $5.35 \%$ cases of patients conceived following IVF treatment.

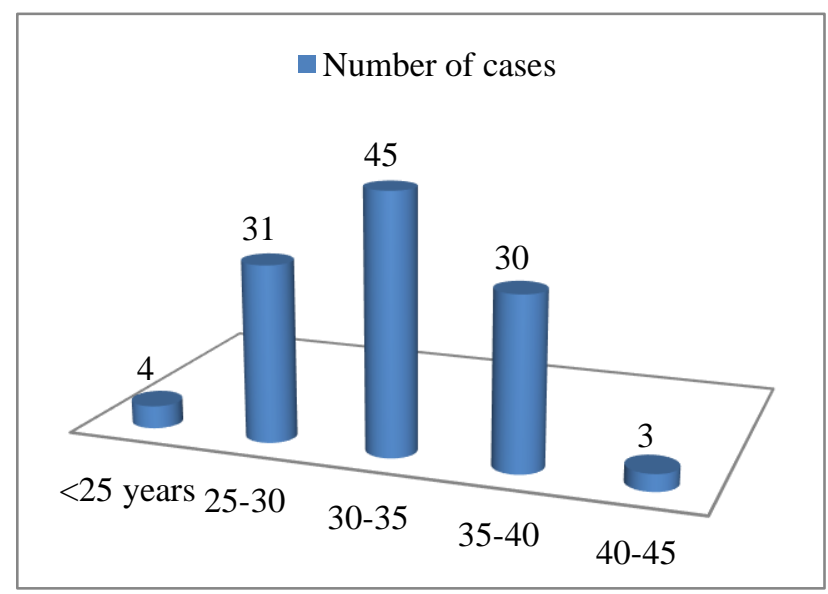

Figure 1: Age distribution of cases.

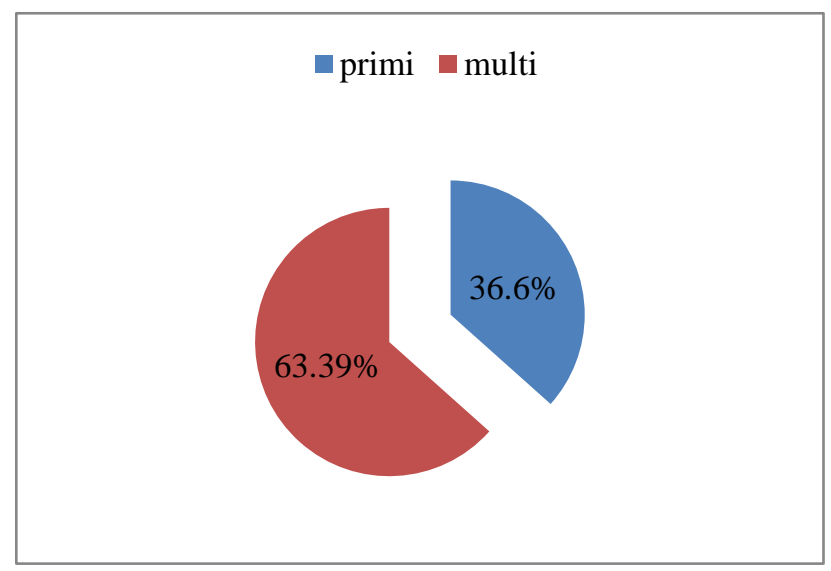

Figure 2: Distribution of parity among cases.

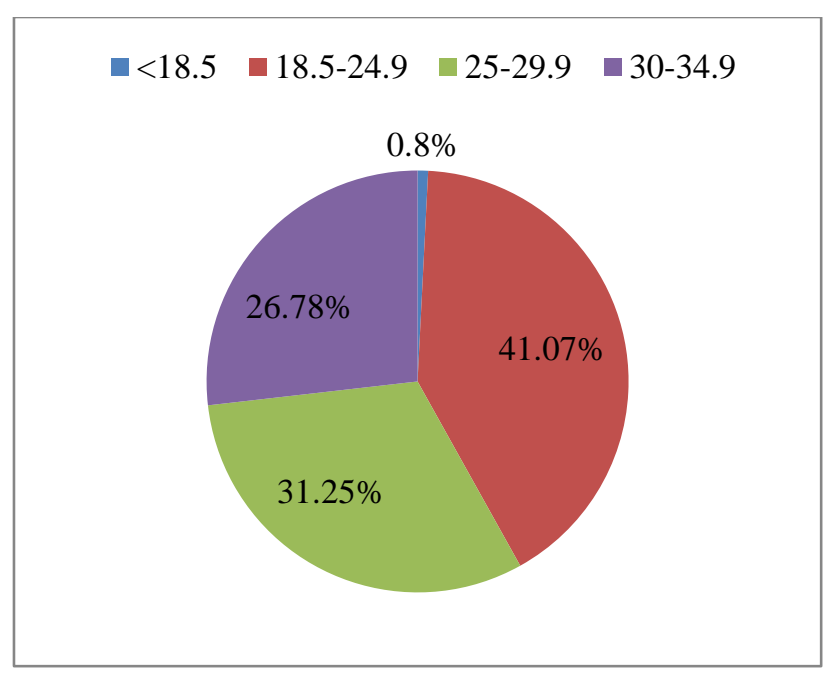

Figure 3: Distribution of BMI among cases.

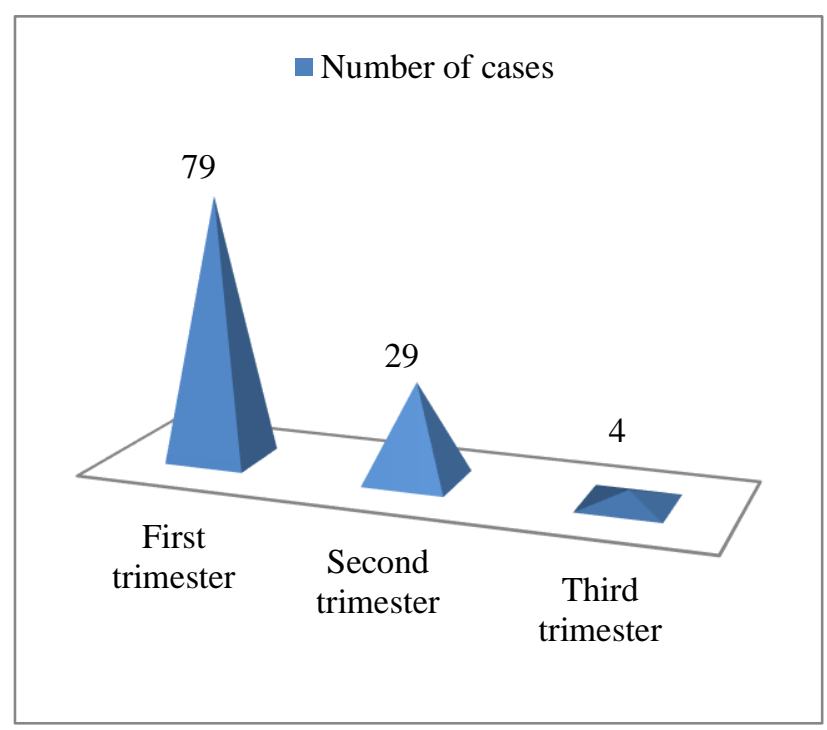

Figure 4: Gestational age of diagnosis.

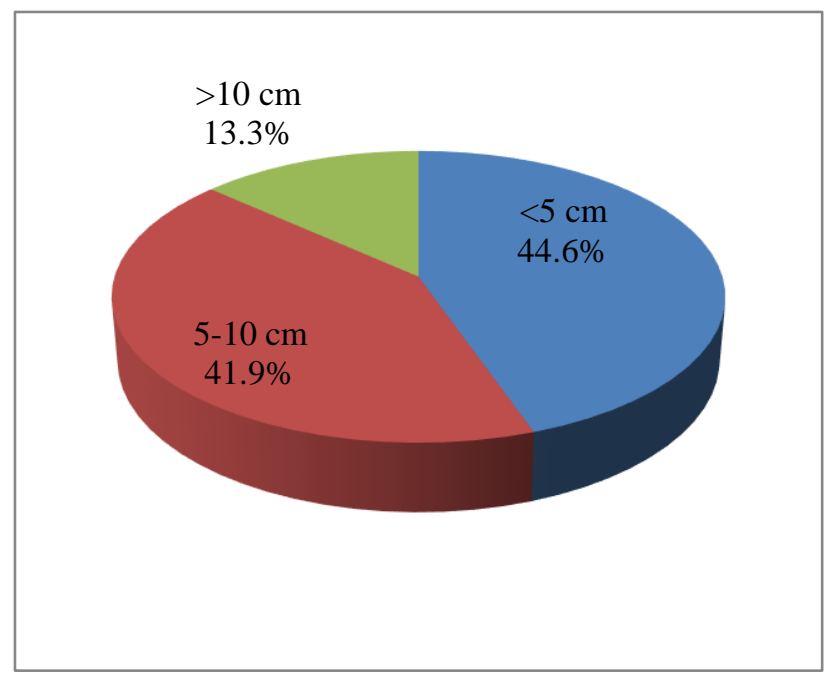

Figure 5: Distribution of myoma according to size in $\mathbf{c m}$. 


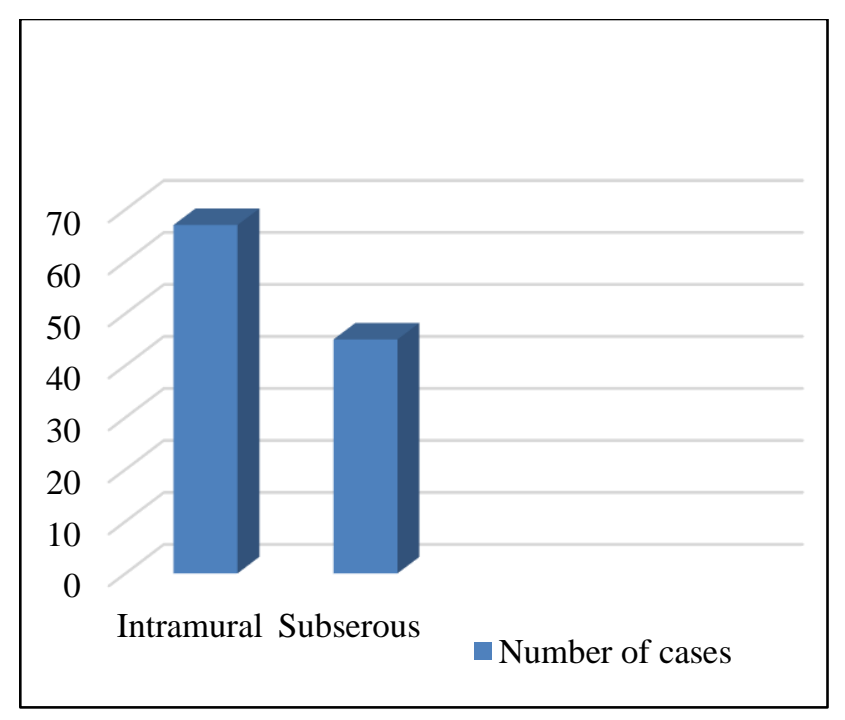

Figure 6: Types of fibroid.

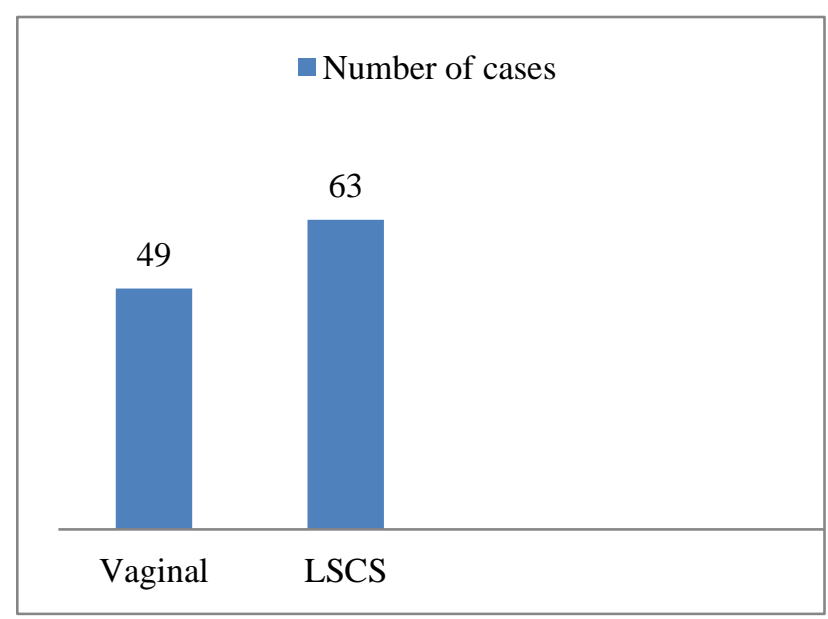

Figure 7: Distribution of mode of delivery.

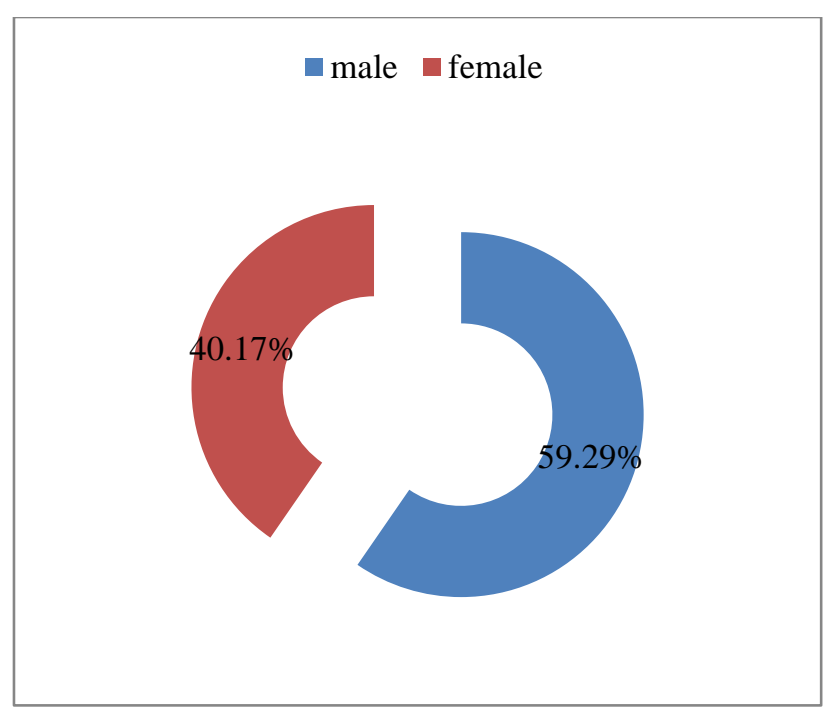

Figure 8: Distribution of sex of babies.

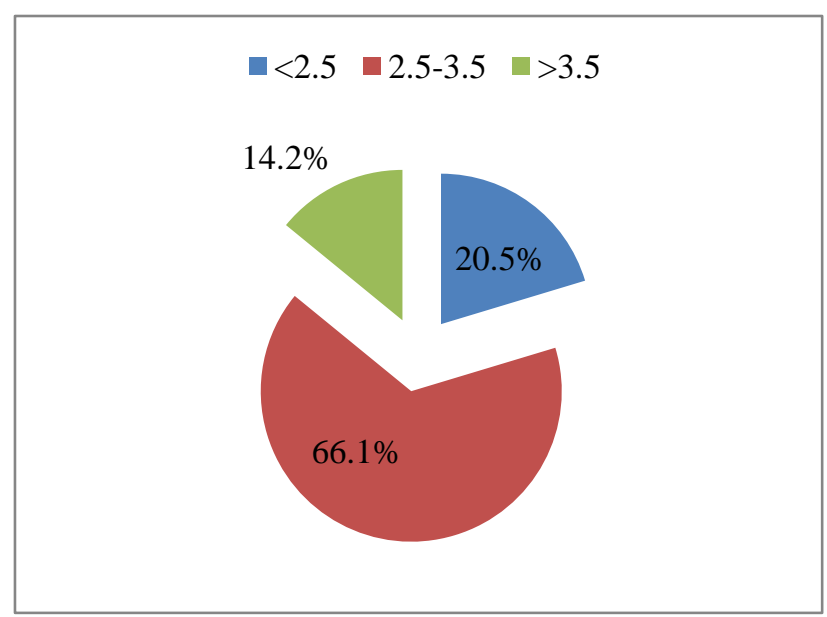

Figure 9: Distribution of baby weight (in kgs).

Table 1: Changes in fibroid during pregnancy.

\begin{tabular}{|lccc|}
\hline $\begin{array}{l}\text { Size of myoma during } \\
\text { pregnancy }\end{array}$ & Increased $(\%)$ & Decreased $(\%)$ & No changes $(\%)$ \\
\hline Number of cases & $41(36.6)$ & $15(13.39)$ & $56(50)$ \\
\hline
\end{tabular}

Table 2: Maternal complications.

\section{Maternal complications}

\begin{tabular}{|ll|}
\hline Maternal complications & $8(7.2)$ \\
\hline Preterm labour & $12(10.71)$ \\
\hline PPH & $20(17.8)$ \\
\hline Gestational hypertension & $43(38.39)$ \\
\hline GDM & $11(9.8)$ \\
\hline Anaemia & $3(2.6)$ \\
\hline Placenta previa & $65(58.03)$ \\
\hline Prolonged hospital stay & \\
\hline
\end{tabular}

On antenatal visits size of the uterus remained corresponding to gestational age in $56.25 \%$ of cases and was more than the period of amenorrhoea in $39.2 \%$ of cases and less than the period of amenorrhoea in $4.4 \%$ cases. Majority of the fibroids were arising from body of uterus, that is about $94.6 \%, 5.3 \%$ were cervical fibroid. $44.6 \%$ of the fibroids were with size less than $5 \mathrm{~cm}$ and $41.9 \%$ with size between 5 to $10 \mathrm{~cm}$ and $13.3 \%$ myomas 
with size more than $10 \mathrm{~cm}$ (Figure 5).59.8\% myomas were intramural type and $40.17 \%$ subserous type of leomyomas (Figure 6).

There was no change in size of fibroids in $50 \%$ of cases during pregnancy, increase in size $36.6 \%$ of cases and decrease in $13.39 \%$ of cases (Table 1).6\% of cases gave history of admission for symptoms of red degeneration. Of the total cases $43.75 \%$ delivered vaginally and $56.25 \%$ delivered by caesarean (Figure 7).

Induction of labour was done in $12.5 \%$ of cases. Concurrent myomectomy with caesarean done in $26.7 \%$ of cases. During caesarean size and number of fibroids were assessed. $36 \%$ fibroids were of same size, $28.5 \%$ had size more than the size what found in ultrasound and less size compared to scan finding in $19 \%$, in $11 \%$ findings were not mentioned and in $4.7 \%$ no fibroids were detected. Uterine artery ligation was done in $10.71 \%$ of cases. Prolonged hospital stay of more than five days in $58.3 \%$ of cases. Incidence of postpartum haemorrhage in $10.71 \%$, and blood transfusion was done in $6.25 \%$ of cases. History of abortion was seen in $19.7 \%$ of cases, majority were of 1 st trimester abortion. $38.39 \%$ cases of gestational diabetes, $17.8 \%$ cases of gestational hypertension, $9.8 \%$ of anaemia, $7.2 \%$ of preterm labour, $2.8 \%$ of placenta praevia were the common maternal complications (Table 2).

$92.8 \%$ of cases belonged to gestational age more than 37 weeks. Of the total babies $59.29 \%$ male babies and $40.7 \%$ female babies (Figure 8).

$88.4 \%$ fetuses were in cephalic presentation and $11.6 \%$ were in breech presentation. $66.07 \%$ of the belonged to babies with birth weight between $2.5 \mathrm{kgs}$ and $3.5 \mathrm{kgs}$. $20.5 \%$ birth weight less than $2.5 \mathrm{kgs}, 14.2 \%$ weight more than $3.5 \mathrm{kgs}$ (Figure 9).

99.1\% babies were live babies. Apgar was normal in $99.1 \%$ of babies. NICU admission in $4.4 \%$ of cases.

\section{DISCUSSION}

During pregnancy in some studies the prevalence of uterine fibroids ranges from 1.6 to $10.7 \%$ and the prevalence varies from one trimester to another. ${ }^{23,24}$ Incidence of fibroid in this study is $0.71 \%$ which is less compared to many of the studies. Reason may be due to inclusion of cases only those beyond 28 weeks. Similar to Baird et al around $70 \%$ of cases belonged to age group between 30 to 40 years. $^{25,26}$ Prevalence rate is highest in first trimester because some fibroids increase in size during this semester. ${ }^{27}$ Majority of fibroids were diagnosed in the first trimester scan. Half of the cases there was no change in size of fibroids during pregnancy. Similar observation was found in studies by Aharoni et al, Rosati et al.

Uterine fibroids risk was increased with enhanced visceral fat area, BMI, waist circumference, waist-height ratio and waist-hip ratio in many studies, similar to that BMI was more than 25 in $58 \%$ of the cases in this study also. ${ }^{28,29}$ Multiparous patients were more in this study unlike most of epidemiologic studies. Parity is said to be protective in many studies. ${ }^{30,31,33}$ More than half of cases in the study, the uterine size was corresponding to period of amenorrhoea similar observation by Lee $\mathrm{HJ}$ et al also.

Fibroids arising from body of uterus were predominant when studied about site of myomas. And the commonest type of fibroid were intramural. Very large fibroids were only $13.3 \%$ among the total patients. During pregnancy half of the fibroids showed no change in size during pregnancy. Commonest symptom encountered in pregnancy was pain. ${ }^{9,14,34}$ Incidence of caesarean was more compared to vaginal deliveries, study by Karlson et al also showed similar result. ${ }^{35}$

Anaemia was one of the complication seen in these patients. History abortion also was there in most of the multiparous patients studied. Slightly higher incidence of preterm birth, placenta praevia, oligamnios like in most of the studies. ${ }^{36-38,42}$

Incidental myomectomy also done in few cases. Duration of hospital stay was more than five days in more than half of the cases. Incidence of postpartum haemorrhage, uterine artery ligation during caesarean, blood transfusion were high in these cases like observation in most of the studies. ${ }^{36,39-42}$

There was higher incidence of malpresentation. ${ }^{36,43}$ Incidence of intrauterine growth restriction was also high. ${ }^{36,44}$ There was not much difference in Apgar scores of the babies. Main cause for NICU stay was due to neonatal hyperbilirubinaemia.

\section{CONCLUSION}

Even though majority of fibroids are asymptomatic during pregnancy fibroids may cause changes in maternal and fetal outcome depending on site, size and number of fibroids. There is slightly higher incidence of caesarean delivery, preterm birth, placenta previa malpresentation and intrauterine growth restriction in fibroid complicating pregnancies. Regular antenatal care and antenatal mapping of fibroids can help in reducing the fetomatenal complications.

Funding: No funding sources

Conflict of interest: None declared

Ethical approval: The study was approved by the Institutional Ethics Committee

\section{REFERENCES}

1. Cramer SF, Patel A. The frequency of uterine leiomyomas. Am J ClinPathol. 1990;94(4):435-8

2. Somigliana E, Vercellini P, Daguati R, Giorgi O, Crossignani PG. Fibroids and female reproduction: a 
critical analysis of the evidence. Hum Reprod Update. 2007;13(5);465-76.

3. Guo XC, Segars JH. The impact and management of fibroids for fertility: an evidence-based approach. Obstet Gynecol Clin North Am. 2012;39(4):521-33.

4. Qidwai GI, Caughey AB, Jacoby AF. Obstetric outcomes in women with sonographically identified leiomyomata. Obstet Gynecol. 2006;107;376-82.

5. Burton CA, Grimes DA, March CM. Surgical management of leiomyomata during pregnancy. Obstet Gynecol.1989;74(5):707-9.

6. Rice JP, Kay HH, Mahony BS. The clinical significance of uterine leiomyomas in pregnancy. Am J Obstet Gynecol.1989;160:1212-6.

7. Cooper NP, Okolo S. Fibroids in pregnancy common but poorly understood. Obstet Gynecol Surv. 2005;60(2):132-8.

8. Vivo A, Mancuso A, Giacobbe A, Savasta LM, Dominici RD, Dugo N, et al. Uterine myomas during pregnancy: a longitudinal sonographic study. Ultrasound Obstet Gynecol. 2011;37(3):361-5.

9. Katz VL, Dotters DJ, Droegemueller W. Complications of uterine leiomyomas in pregnancy. Obstet Gynecol. 1989;73(4):593-6.

10. Stout MJ, Odibo AO, Graseck AS, Macones GA, Crane JP, Cahill AG. Leiomyomas at routine secondtrimester ultrasound examination and adverse obstetric outcomes. Obstet Gynecol. 2010;116(5):1056-63.

11. Cook H, Ezzati M, Segars JH, McCarthy D. The impact of uterine leiomyomas on reproductive outcomes. Minerva Ginecol. 2010;62(3):225-36.

12. Aharoni A, Reiter A, Golan D, Paltiely Y, Sharf M. Patterns of growth of uterine leiomyomas during pregnancy. A prospective longitudinal study. $\mathrm{Br} \mathrm{J}$ Obstet Gynaecol. 1988;95(5):510-3.

13. Rosati P, Exacoustòs C, Mancuso S. Longitudinal evaluation of uterine myoma growth during pregnancy. A sonographic study. J Ultrasound Med. 1992;11(10):511-5.

14. Lev-Toaff AS, Coleman BG, Arger PH, Mintz MC, Arenson RL, Toaff ME. Leiomyomas in pregnancy: sonographic study. Radiology. 1987;164(2):375-80.

15. Zimmermann A, Bernuit D, Gerlinger C, Schaefers M, Geppert K. Prevalence, symptoms and management of uterine fibroids: an international internet-based survey of 21,746 women. BMC Women's Health. 2012;12(1):1-1.

16. Carolis SD, Fatigante G, Ferrazzani S, Trivellini C, Santis LD, Mancuso S, et al. Uterine myomectomy in pregnant women. Fetal Diagn Ther. 2001;16(2):1169.

17. Parker WH. Etiology, symptomatology, and diagnosis of uterine myomas. Fertil Steril. 2007;87(4):725-36.

18. Muram D, Gillieson M, Walters JH. Myomas of the uterus in pregnancy:ultrasonographic follow-up. Am J Obstet Gynecol. 1980;138(1):16-9.

19. Winer-Muram HT, Muram D, Gillieson MS. Uterinemyomas in pregnancy. J Can Assoc Radiol. 1984;35(2):168-70.
20. Gabbe SG, Niebyl JR, Simpson JL. Obstetrics: Normal and problem pregnancies. 4th ed. Pennsylvania: Churchill Livingstone; 2008: 739.

21. Michalas SP, Oreopoulou FV, Papageorgiou JS. Myomectomy during pregnancy and caesarean section. Hum Reprod. 1995;10(7):1869-70.

22. Ehigiegba AE, Ande AB, Ojobo SI. Myomectomy during cesarean section. Int J Gynaecol Obstet. 2001;75(1):21-5.

23. Coronado GD, Marshall LM, Schwartz SM. Complications in pregnancy, labor and delivery with uterine leiomyomas: a population-based study. Obstet Gynecol. 2000;95(5):764-9.

24. Laughlin SK, Baird DD, Savitz DA, Herring AH, Hartmann KE. Prevalence of uterine leiomyomas in the first trimester of pregnancy: an ultrasoundscreening study. Obstet Gynecol. 2009;113(3):630-5.

25. Baird DD, Dunson DB, Hill MC, Cousins D, Schectman JM. High cumulative incidence of uterine leiomyoma in black and white women: ultrasound evidence. Am J Obstet Gynecol. 2003;188(1):100-7.

26. Shavell VI, Thakur M, Sawant A, Kruger ML, Jones TB, Singh M, et al. Adverse obstetric outcomes associated with sonographically identified large uterine fibroids. Fertil Steril. 2012;97(1):107-10.

27. Cooper NP, Okolo S. Fibroids in pregnancy-common but poorly understood. Obstet Gynecol Surv. 2005;60(2):132-8.

28. Klatsky PC, Tran ND, Caughey AB, Fujimoto VY. Fibroids and reproductive outcomes: a systematic literature review from conception to delivery. Am J Obstet Gynecol. 2008;198(4):357-66.

29. Sun K, Xie Y, Zhao N, Li Z. A case control study of the relationship between visceral fat and development of uterine fibroids. Experiment Therapeut Med. 2019;18(1):404-10.

30. Chen CR, Buck GM, Courey NG, Perez KM, Wactawski-Wende J. Risk factors for uterine fibroids among women undergoing tubal sterilization. Am J Epidemiol. 2001;153(1):20-6.

31. Okolo S. Incidence, aetiology and epidemiology of uterine fibroids. Best Pract Res Clin Obstet Gynecol. 2008;22(4):571-88.

32. Wise LA, Palmer JR, Harlow BL, Spiegelman D, Stewart EA, Adams-Campbell LL, et al. Reproductive factors, hormonal contraception, and risk of uterine leiomyomata in African-American women: a prospective study. Am J Epidemiol. 2004;159(2):11323.

33. Marshll LM, Spiegelman D, Goldman MB, Manson JE, Colditz GA, Barbieri RL, et al. A prospective study of reproductive factors and oral contraceptive use in relation to the risk of uterine leiomyomata. Fertil Steril. 1998;70(3):432-9.

34. Lee HJ, Norwitz ER, Shaw J. Contemporary management of fibroids in pregnancy. Rev Obstet Gynecol. 2010;3(1):20-7.

35. Karlsen K, Kesmodel SU, Mogensen O, Humaidan P, Ravn P. Relationship between a uterine fibroid 
diagnosis and the risk of adverse obstetrical outcomes: a cohort study. BMJ Open. 2020;10(2):032104.

36. Noor S, Fawwad A, Sultana R, Bashir R, Qurat-ul-ain, Jalil H, et al. Pregnancy with fibroids and its and its obstetric complication. J Ayub Med Coll Abbottabad. 2009;21(4):37-40.

37. Ezzedine D, Norwitz E. Are women with uterine fibroids at increased risk for adverse pregnancy outcome? Clin Obstet Gynecol. 2016;59(1):119-27

38. Ciavattini A, Clemente N, Carpini GD, Giuseppe JD, Giannubilo SR, Tranquilli AL. Number and size of uterine fibroids and obstetric outcomes. The journal of maternal-fetal and neonatal medicine: the official journal of the European Association of Perinatal Medicine, the Federation of Asia and Oceania Perinatal Societies, the International Society of Perinatal Obstet. Res Gate. 2015;28(4):484-8.

39. Parazzini F, Tozzi L, Bianchi S. Pregnancy outcome and uterine fibroids. Best Pract Res Clin Obstet Gynaecol. 2016;34:74-84.

40. Kramer MS, Berg C, Abenhaim H, Dahhou M, Rouleau J, Mehrabadi A, et al. Incidence, risk factors, and temporal trends in severe postpartum hemorrhage. Am J Obstetr Gynecol. 2013;209(5):441-7.

41. Navid S, Arshad S, Qurat-ul A, Meo RA. Impact of leiomyoma in pregnancy. JAMC. 2012;24(1):90-2.

42. Zaima A, Ash A. Fibroid in pregnancy: characteristics, complications, and management. Postgrad Med J. 2011;87(1034):819-28.

43. Zhao R, Wang X, Zou L, Li G, Chen Y, Li C, et al. Adverse obstetric outcomes in pregnant women with uterine fibroids in China: A multicenter study involving 112,403 deiveries. PLoS One. 2017;12(11):0187821.

44. Dasgupta A, Santra D, Talukdar A, Ghosh U, Narayan S, Dasgupta S. Obstetric outcomes with large fibroids in pregnancies near term: a study in a tertiary care centre in Rural India. Obstet Gynecol Int J. 2017;7(2):00244.

Cite this article as: Sankaran SM, Pillai JS. Fetomaternal outcome in fibroid complicating pregnancy: a retrospective study. Int J Reprod Contracept Obstet Gynecol 2021;10:2613-9. 